\title{
Immersive Gamification Platform for Manufacturing Shopfloor Training
}

\author{
Zhao Zhiqiang*, Toh Da Jun, Ding Xiaoming, Ng Keng Chong, Sin See Choon, Wong Yuen Choe \\ Nanyang Polytechnic, Singapore \\ *Correspondence: zhao_zhiqiang@nyp.edu.sg, Tel: (0065)-65500921
}

\begin{abstract}
This paper shares our work in developing and implementing an immersive gamification training platform for students who undergo manufacturing shopfloor training at the School of Engineering, Nanyang Polytechnic, Singapore. In this gamification training platform, we developed a virtual manufacturing shopfloor that is identical to the actual shopfloor located in the school. Students have the freedom to learn the manufacturing shopfloor operations and safety acts through the various game scenarios and training tasks which include workshop safety, CNC machine introduction, CNC machining dynamics, MES, etc. In addition, the assessment feature with immediate feedback were embedded within the gamification platform, which aim to help students to assess their level of understanding and help teachers to monitor the learning progress of their students. To investigate the impact of this gamification training platform on students' learning outcome and motivation in manufacturing shopfloor technologies and safety acts, a pilot study was conducted in AY2018 semester 2 for a total 134 students from 4 classes of digital \& precision engineering diploma. It is found that gamification can be integrated effectively into manufacturing education to motivate students and enhance their learning effectiveness. Based on the collected data from the technical quizzes and satisfactory survey, the results showed that the integration of gamification into the classroom learning not only added a stimulating and captivating game-like layer to the learning experience of the students, but also provided a safe environment for students to learn without fear of making errors. Challenges faced in implementing this gamification training platform will also be discussed in this paper.
\end{abstract}

Keywords: Gamification education; manufacturing shopfloor; virtual reality; student engagement

\section{Introduction}

Learning is an active and participatory process and requires motivation to begin and continue the journey. Standard lessons for manufacturing shopfloor training are sometimes considered boring and ineffective by some students. Motivation can therefore be a problem, especially when students do not have enough technical background to catch the objective of given learning activities. Moreover, standard training approaches via literal manuals and verbal instructions are inefficient for students to familiarize with the manufacturing systems and operational procedures of manufacturing shopfloor. Considering the common constraints at the shopfloor such as limited facilities, compact schedule, insufficient instruction hours, cost of equipment, students often do not have sufficient hand-on practices, and thus face difficulty in operating the manufacturing systems such as CNC machines and Manufacturing Execution System (MES).

Gamification is becoming more prevalent in education because of its perceived ability to motivate students and make their learning activities more active and participatory [2]. In the literature review for gamification in education [3], the authors confirmed the increasing interest in gamification in education by using Google Scholars. In "Does Gamification Work? - A Literature Review of Empirical Studies on Gamification" [1], the researchers took a structured approach to determining the effectiveness of gamification. In practice, Bradley Wiggins discussed how games and simulations were applied in the classroom of higher education [4]. Their research showed that gamification in education produces positive effects and benefits for a majority of current studies. 
In recent years, gamification education has been applied in many disciplines such as math, health, aerospace, business, computer science, life and chemistry, digital media, etc. $[5,6]$. However, little emphasis has been given to the gamification education for manufacturing shopfloor training. Gamifying shopfloor machines and operations can give students a support beyond the shopfloor, help familiarizing with shopfloor systems, increase motivation, and reduce their fear while approaching to actual machines. Gamification can be a better education environment for shopfloor training, not only taking advantage of the gaming technology in production, but also transferring the gaming knowledge and expertise on game design to motivate and train students. This paper presents our work on developing and implementing the gamification platform for manufacturing shopfloor training at School of Engineering of Nanyang Polytechnic. It first covers the development of the gamification platform development and its elements. Subsequently, it presents the creation of gaming tasks to reinforce our teaching curriculum. After that, it describes the implementation results of the gamification platform in enhancing students' learning experience. Finally, the evaluation and discussion over the gamification training platform are given to provide educators with our insights in how to integrate gamification principles into existing curriculums and enhance its effectiveness.

\section{Development of Immersive Gamification Platform}

The aim of the gamification platform is to reinforce our course concepts and enhance students' learning experience beyond the classroom. This gamification platform and its tasks are designed to fit into the current curriculum of digital precision engineering diploma at our school. It is built to train the various manufacturing technologies applied in the manufacturing shopfloor. It also plays an important role in preparing students before they approach to the manufacturing shopfloor operating actual manufacturing systems (such as CNC machines, CMM and MES) for their learning activities and final year projects. Educational gamification seeks to add game-like concepts to a learning process and impart educational benefit. The gamification platform presented in this paper thus focus on achieving four gaming aspects, i.e. gamification reality environment, goal-focused tasks, assessment, and reward mechanisms.

\subsection{Gamification Reality Environment}

The immersive gamification environment should demonstrate the real-world contexts in a virtual gaming world to foster motivation and enhance learning experiences regarding of given teaching contents. One common issue of gamification education is "The gaming environment is not really identical to the real environment". Trainees will still confront with uncertain obstacles and frustrations in front of actual objects and situations because they need cope with the variations among virtual gaming contexts and real ones. Responding to this challenge, we strive to design the gamification environment and contexts identical to the ones of the actual manufacturing shopfloor of our department.

Figure 1 (a) shows the real manufacturing shopfloor of School of Engineering, which supports students' training and their final year projects. The shopfloor comprises of various manufacturing systems including CNC machines (including milling, turning, turn-mill center, grinding, etc.), CMM, EDM, MES from different makes and models as listed in Table 1. Compared to the presented virtual gamification environment as can be seen in Figure 1 (b), it is obvious that all gaming contents and elements are identical to the actual shopfloor in terms of their layout, model, quantity, feature, dimension, appearance, etc. The gaming elements of serval real components are displayed in Table 1 . Besides the manufacturing systems, other features and facilities (such as tables \& chairs, workstations, work pieces \& tools, distinguishers, first aid kit, lighting, etc.) are also created in the gamification environment to realize the full sense of reality. With the practices from such a 'real' virtual gamification environment, students are expected to be able to seamlessly transform their skills gained from the game to the actual shopfloor operations with little transition barrier. 


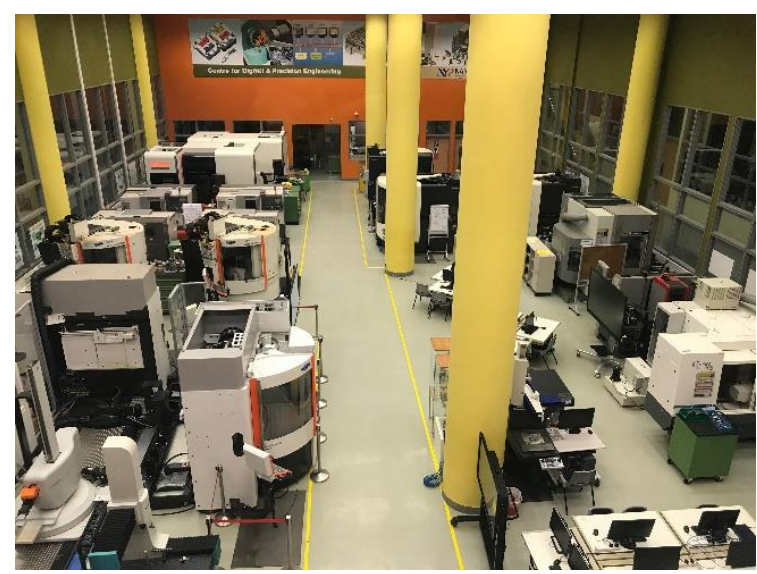

(a)

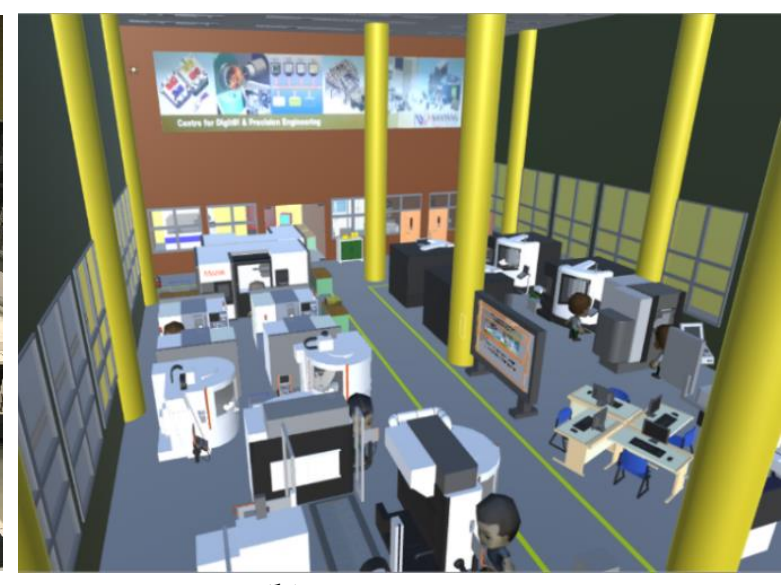

(b)

Figure 1. Comparison of the real and virtual shopfloor: (a) The physical manufacturing shopfloor; (b) The immersive gamification environment

Table 1. List of Manufacturing Systems and Gamification Elements

\begin{tabular}{|c|c|c|c|}
\hline $\begin{array}{l}\text { Machine \& } \\
\text { facility }\end{array}$ & Model \& type & Quantity & Gaming element \\
\hline \multirow{10}{*}{ CNC machines } & DMU 40 Evo (5 axis milling) & 4 & \\
\hline & Mikron 400 U (5 axis milling) & 1 & \\
\hline & Mikron 500 LP (3 axis milling) & 1 & \\
\hline & Mikron HSM 400 (HSM milling) & 2 & \\
\hline & DMU 50 Evo (5 axis milling) & 1 & \\
\hline & Kern 500 Micro (micro milling) & 1 & \\
\hline & Okuma LB3000 (turning) & 4 & \\
\hline & Amada MS G3 (profile grinding) & 1 & \\
\hline & Studer S31 (grinding) & 1 & \\
\hline & Mazak I-200 (turn-mill centre) & 2 & \\
\hline \multirow{2}{*}{$\mathrm{CMM}$} & Zeiss DuraMax & 1 & \\
\hline & Wenzel Xorbit & 1 & \\
\hline EDM machines & AgieCharmilles FO 350 & 1 & \\
\hline MES & $\begin{array}{l}\text { 3R ITC System (including CNC } \\
\text { machines, CMM, robot arm, } \\
\text { control centre, tool magazine, } \\
\text { EDM, etc.) }\end{array}$ & 1 set & \\
\hline $\begin{array}{l}\text { Other facilities } \\
\text { and systems }\end{array}$ & $\begin{array}{l}\text { Toolbox, work piece, material, } \\
\text { Table, chair, distinguisher, first } \\
\text { aid, etc. }\end{array}$ & - & \\
\hline
\end{tabular}

\subsection{Gamification Training Task}

Effectively integrating gamification into education demands a thoughtful study of the training contents, learning objectives, and the students involved. After considering the holistic structure of our teaching curriculum and the desired gamification elements and mechanisms for effective training and efficient learning, we strive to achieve the below goals while designing the gamification tasks for manufacturing shopfloor training:

- Scenario-based tasks to make training realistic 
- Gaming driven approach by interactive challenges and quests

- Game-based design to enhance entertainment and engagement experience

- Timed decision-making activities to inspire potential learning passion

- Learn by "doing" with step-by-step process

In this gamification education platform, a total 16 gaming tasks were developed covering the below three topics to support the teaching curriculum for manufacturing shopfloor training:

a) Train the safety awareness and reactive actions of the manufacturing shopfloor

b) Introduce the various manufacturing systems of the manufacturing shopfloor

c) Train and teach the machining techniques, mechanisms, applications, operations, dynamic, and machining methods of different manufacturing systems of the manufacturing shopfloor

\subsubsection{Shopfloor Safety Training}

Safety awareness is important and a compulsory procedure in manufacturing shopfloor by Workplace Safety \& Health Act (WSH). Under this act, all parties must manage risks at work and adhere to safe work procedures. In this gamification platform, three scenario-based gaming tasks were created to reinforce the safety awareness at shopfloor, to cultivate good safety habits, and to promote a strong safety culture for all students in our workplace. Table 2 describes the details of the three safety training tasks including their game scenes, game scenarios, and corresponding training objectives. In the first task (Task 1-1), students need to wear safety suits properly at the entrance of the shopfloor before any other training actives. Once a fire event is triggered (Task 1-2), students must quickly locate the distinguisher and pull out the fire, which may occur at different locations of the shopfloor. Running out of time for this task will evoke system warning. While Task 1-3 is triggered, students need to pick up the oil blotting paper and clean the oil stain appearing at random sites. Through these activities, we want to cultivate students with good safety habits and reinforce their safety awareness. In addition, students can also familiarize with shopfloor layout and the locations of safety facilities.

Table 2. Shopfloor Safety Training Tasks

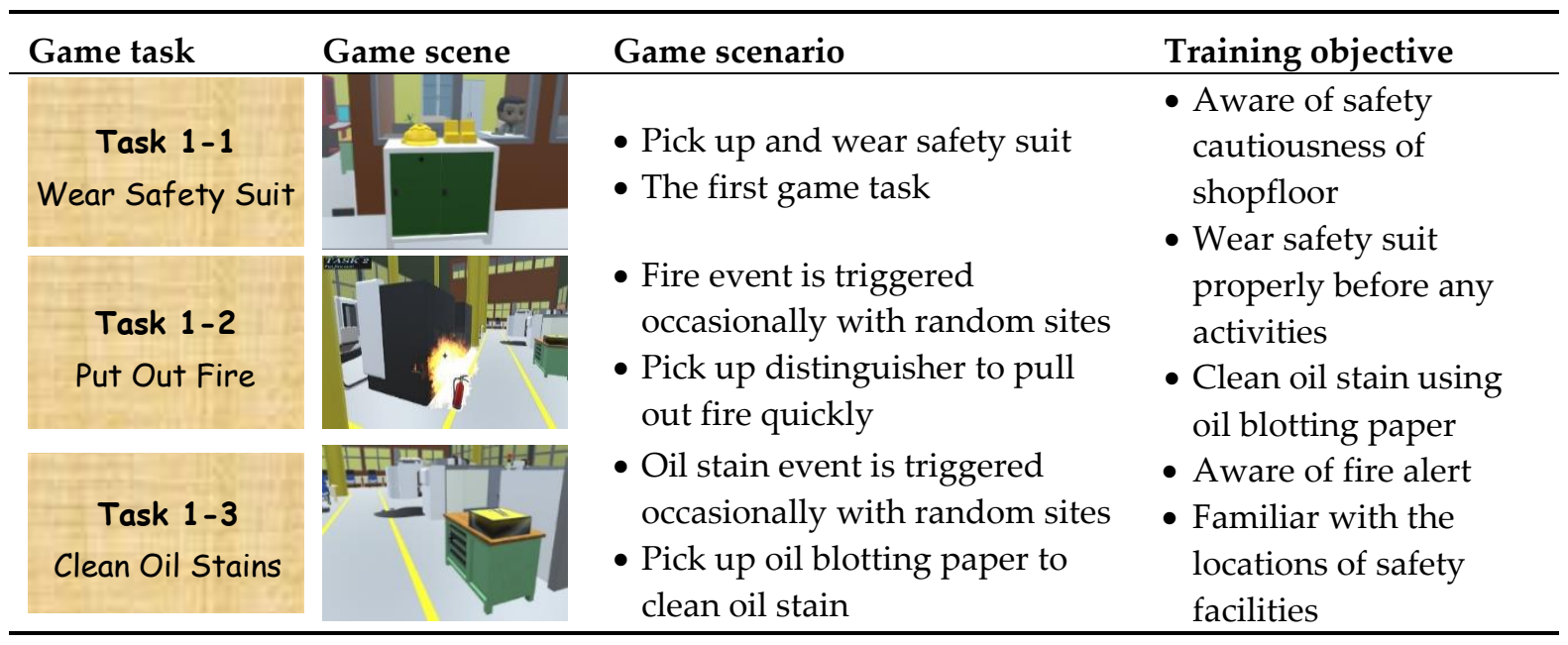

\subsubsection{Manufacturing System Introduction}

Manufacturing system introduction tasks are designed to introduce the various manufacturing systems of the shopfloor. Through the total seven gaming tasks from Task 2-1 to Task 2-7 (as listed in Table 3), students are expected to familiarize with various CNC machines, CMM, EDM, MES, and learn diverse manufacturing technologies of different manufacturing clusters of the shopfloor. To complete these gaming tasks, students need to explore different manufacturing systems, understand their operations and features, and closely view the machine structures and simulations at the virtual gaming environment. 
Table 3. Manufacturing System Introduction Tasks

\begin{tabular}{|c|c|c|c|}
\hline Game task & Game scene & Game scenario & Training objective \\
\hline $\begin{array}{c}\text { Task 2-2 } \\
\text { Learn OKUMA } \\
\text { Turning } \\
\text { Task 2-3 } \\
\text { Learn MIKRON } \\
\text { HSM Milling } \\
\text { Task 2-4 } \\
\text { Learn MAZAK } \\
\text { Turn-Mill } \\
\text { Task 2-5 } \\
\text { Learn AMADA } \\
\text { Grinding } \\
\text { Task 2-6 } \\
\text { Learn EDM System } \\
\text { Task 2-7 } \\
\text { Learn MES System }\end{array}$ & & $\begin{array}{l}\text { Based on the } \\
\text { given jobs, } \\
\text { student should: } \\
\text { - Identify the } \\
\text { right } \\
\text { manufacturing } \\
\text { system } \\
\text { - Collect } \\
\text { appropriate } \\
\text { system } \\
\text { information } \\
\text { - Invoke proper } \\
\text { actions and } \\
\text { operations } \\
\text { - Investigate } \\
\text { machine } \\
\text { controllers and } \\
\text { functions }\end{array}$ & $\begin{array}{l}\text { - Familiarize the layout and } \\
\text { system clusters of the } \\
\text { shopfloor } \\
\text { - Familiarize with various CNC } \\
\text { machines (i.e. } 3 \text { axis milling, } 5 \\
\text { axis milling, turning, HSM } \\
\text { milling, turn-mill and grinding } \\
\text { machine) } \\
\text { - Understand the differences of } \\
\text { different machines (including } \\
\text { axis, design, key components, } \\
\text { configuration, mechanical } \\
\text { structure, tooling system, } \\
\text { functions, operations and } \\
\text { applications) } \\
\text { - Familiarize with EDM } \\
\text { machine (including key } \\
\text { components, configuration, } \\
\text { mechanical structure, tooling } \\
\text { system, functions, operations } \\
\text { and applications) } \\
\text { - Familiarize with MES and its } \\
\text { system elements (including } \\
\text { control centre, robot arm, tool } \\
\text { magazine, CNC machines, } \\
\text { CMM, etc.) }\end{array}$ \\
\hline
\end{tabular}

\subsubsection{Manufacturing System Mechanism and Application}

Six gaming tasks (from 3-1 to Task 3-6 listed in Table 4) are designed for students to learn the manufacturing mechanism, dynamics, functions, methods, and controllers of various manufacturing systems. To complete these tasks, students should find the right machines and operations for specific given jobs, including 3 axis milling, turning, turn-mill, multi-axis machining, drilling, grinding, integrated MES, etc. Through the job executions and simulations without the worry of mistakes and safety issues, students can establish a deep understanding of machining mechanism, dynamics, job operations, functions and machine controllers.

Table 4. Manufacturing System Mechanism and Application Tasks

\begin{tabular}{clll}
\hline Game task & Game scene & $\begin{array}{l}\text { Game scenario } \\
\text { Task 3-1 }\end{array}$ & $\begin{array}{l}\text { Training objective } \\
\text { 3-Axis Milling Job }\end{array}$ \\
$\begin{array}{c}\text { Based on the given jobs, } \\
\text { student should: } \\
\text { - Identify the right } \\
\text { manufacturing } \\
\text { Task 3-2 }\end{array}$ & $\begin{array}{l}\text { Understand the manufacturing } \\
\text { mechanism and functions of } \\
\text { manufacturing systems. }\end{array}$ \\
Turning Job & & $\begin{array}{l}\text { Understand CNC machining } \\
\text { operations, such as } 3 \text { axis }\end{array}$ \\
\hline
\end{tabular}




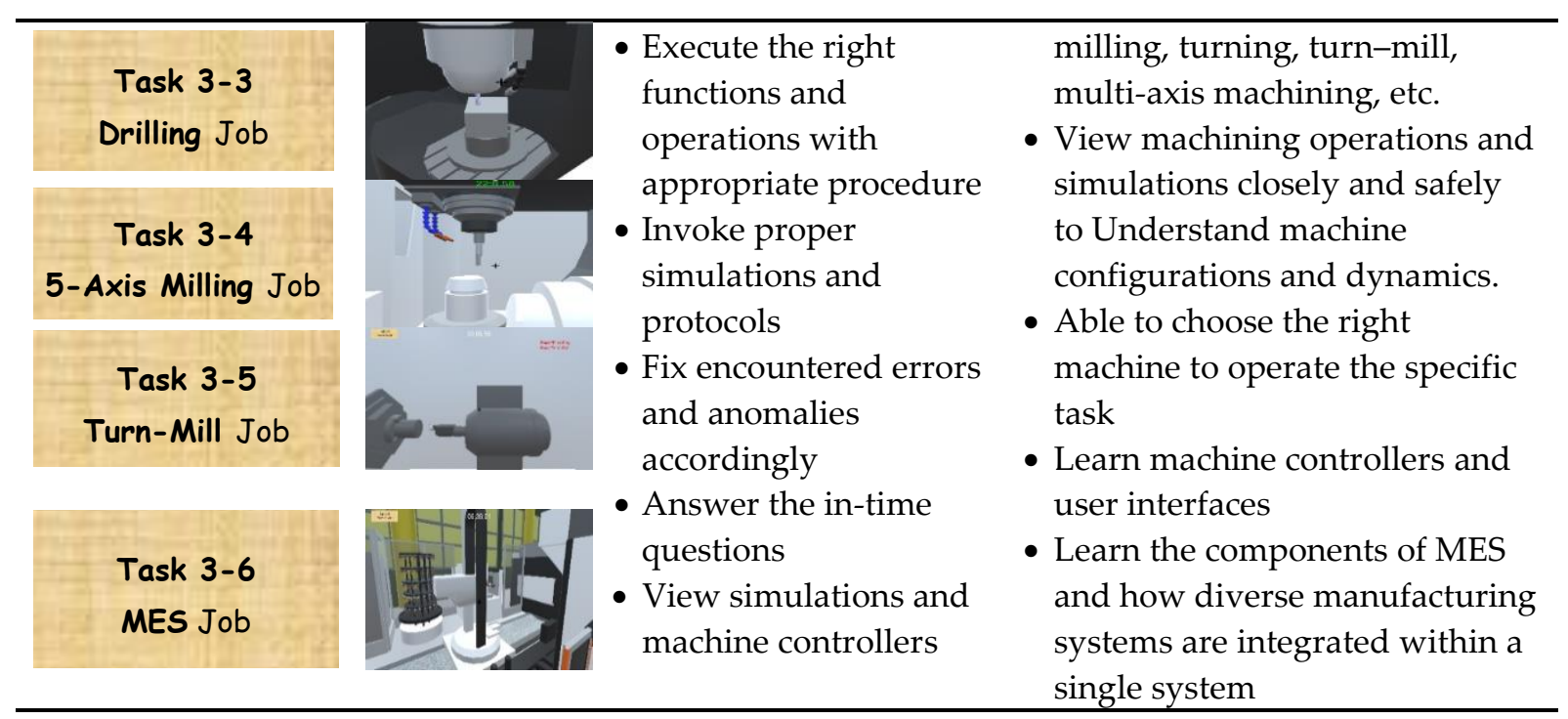

\subsection{Assessment and Reward Mechanism}

Assessment features are built within the gamification platform to assess students' learning and training results. Students can view their training progress and results as shown in Figure 2. A leaderboard is typically used in competitive activities and in encouraging repetitive actions. In this gamification platform, a leaderboard is developed to display students' gaming achievement with their game ranking (in Figure 3). As a coarse-grained technique tool, it provides just-in-time feedback and overall competencies as well as plays as a motivator to encourage little further effort to achieve better results.

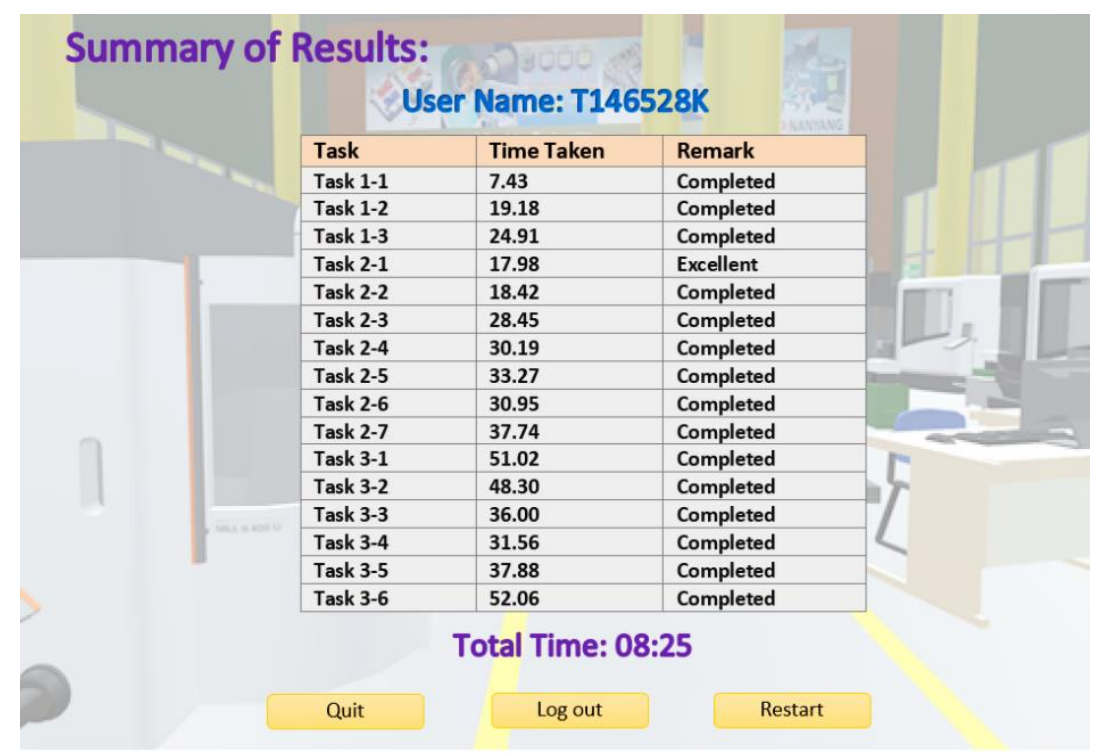

Figure 2. Gamification task assessment 


\begin{tabular}{|c|c|c|c|c|c|c|c|}
\hline \multicolumn{8}{|c|}{ Shopfloor Training Ranking Results } \\
\hline \multicolumn{4}{|c|}{ Recent players: } & \multicolumn{4}{|c|}{ Top10 players: } \\
\hline Index & Name & Time(Seconds) & $\hat{\imath}$ & Award & Rank & Name & Time(Seconds) \\
\hline 1 & $174324 \mathrm{~K}$ & 661 & & (1) & 1 & $173900 \mathrm{~J}$ & 289 \\
\hline 2 & $170809 \mathrm{~S}$ & 396 & & (7) & 2 & $172664 \mathrm{C}$ & 311 \\
\hline 3 & $173900 \mathrm{~J}$ & 423 & & ( & 3 & $163744 y$ & 320 \\
\hline 4 & 170987R & 471 & & & 4 & $175277 \mathrm{~A}$ & 325 \\
\hline 5 & $175169 Y$ & 772 & & & 5 & 1746001 & 326 \\
\hline 6 & $17 \mathrm{C} 111 \mathrm{C}$ & 2658 & & & 6 & $167328 \mathrm{~K}$ & 340 \\
\hline 7 & $17 \mathrm{C} 104 \mathrm{~W}$ & 2879 & & & 7 & VENOM & 353 \\
\hline 8 & $17 \mathrm{C} 106 \mathrm{Q}$ & 2601 & & & 8 & 171747E & 354 \\
\hline 9 & 17C102A & 2251 & & & 9 & E1692834L & 357 \\
\hline 10 & 17C114E & 1833 & & & 10 & $175674 R$ & 368 \\
\hline 11 & 174323E & 637 & & & & & \\
\hline 12 & $160955 \mathrm{~F}$ & 577 & $\checkmark$ & & & & \\
\hline
\end{tabular}

Figure 3. Leaderboard for gaming results

\section{Implementation and Results}

The shopfloor immersive gamification training platform was implemented at the manufacturing shopfloor of Nanyang Polytechnic in AY2018 semester 2. It was launched as an e-Learning platform for those students just before having their learning activities and final year projects at the manufacturing shopfloor. A total 134 students from 4 classes of digital precision engineering diploma are involved in the gamification evaluation. To investigate the effectiveness of the gamification platform, a set of technical quizzes and game feedback survey are produced. The technical quizzes include 16 questions covering the training objectives based on the digital manufacturing shopfloor training curriculum. The game feedback survey contains 10 questions focusing on the psychological need and game satisfaction of all participants. Before the game play, teachers had taught the knowledge of the manufacturing systems of the shopfloor in classroom verbally and their self-learning with literal training documents. Class 1 and Class 2 completed the technical quizzes before playing their gaming tasks, while Class 3 and Class 4 completed the technical quizzes after they played the gaming tasks. Table 5 shows the comparison of the results of technical quizzes by the 4 groups respectively. The average scores of Class 1 and Class 2 are 53 and 56 respectively. The scores Class 3 and 4 are 67 and 68 respectively. It showed an overall $15 \%$ learning improvement from game play. Regarding of the fail rate (means $<50 \%$ correct rate), 16\% (i.e. 6 students) of Class 1 and 37\% (i.e. 10 students) of Class 2 failed in their quizzes. In contrast, only $6 \%$ (i.e. 2 students) of Class 3 and 3\% (i.e. 1 student) of Class 4 failed in their quizzes. It revealed a significant improvement by use of gamification education in leveling up the fundamental knowledge of manufacturing systems. Our finding implied that the gamification education is much efficient in helping those weak learners, for whom classroom teaching is less effective, reaching a satisfactory knowledge level in the shopfloor technology training.

Among the total collected 122 game feedback and satisfactory surveys, the 93\% (i.e. 113 students) agreed that the gaming play had much helped them in familiar with the manufacturing systems of the shopfloor. They are more confident in operating CNC machines with much less fear of making errors. The $91 \%$ of participants responded that the game play had deepened their comprehensive knowledge in understanding diverse manufacturing systems of the shopfloor. The $76 \%$ (i.e. 99 students) indicated that they would like to have such gamification in other modules in our school.

Table 5. Comparison of the Results of Technical Quizzes

\begin{tabular}{lllll}
\hline Items & Class 1 & Class 2 & Class 3 & Class 4 \\
\hline Student number & 38 & 27 & 35 & 34 \\
\hline
\end{tabular}




\begin{tabular}{lllll}
\hline Gaming tasks? & before & before & after & after \\
Average score $(\% 100)$ & 56 & 53 & 67 & 68 \\
Fail rate & $16 \%$ & $37 \%$ & $6 \%$ & $3 \%$ \\
$(<50 \%$ correct rate $)$ & $(6$ students $)$ & $(10$ students $)$ & $(2$ students $)$ & $(1$ student $)$ \\
\hline
\end{tabular}

The overall evaluation revealed that the gamification platform had a positive impact in engaging students in their learning. It was also observed that students prone to involve in more discussions, engagement and teamwork while playing game, even for those 'quiet' students in classroom. Teachers also feel empowered to start integrating gamification elements and mechanisms into their curriculum. It is concluded that gamification can be integrated effectively into manufacturing education to motivate students and enhance learning effectiveness, as well as provide a safe environment for students to learn without fear of making errors.

\section{Discussion and Recommendation}

Based on the findings through the implementation and evaluation of the gamification education platform in our department, we would like to share our insights in several arguments as below:

a) Gamification environment should be identical to the real shopfloor

Manufacturing shopfloor training is in-nature a practical training and its objective is to train students in operating different CNC machines. Apparently, gamification training can be much efficient if the virtual machines in game environment are identical to the real machines of the shopfloor. Students can therefore easily match what they have learnt through game play with the real systems with fewer variations. Our survey supported this finding. Moreover, we recommended to setup gamification stations at the shopfloor, students can thus immediately compare the actual components with their virtual avatars. We have done so, and the feedback is very positive.

b) Gamification is an effective e-Learning platform

Manufacturing shopfloor training often requires supportive activities, facility sharing, material \& tool consumption, operational guidance, as well as progress tracking and interactions. With the gamification platform, students can practice training tasks without physical and time constraints, and learn from mistakes that cannot be afforded at actual shopfloor. Our students and instructors had confirmed the gamification platform as an efficient e-Learning platform.

c) Gamification cannot replace classroom teaching and hand-on training

Our experience indicated that gamification platform works effectively in preparing students with the general knowledge of manufacturing systems such as machine features, applications, operations, etc. Gamification can also lead to building up internal motivation to engage with real activities at shopfloor. However, it is hard to expect gamification platform covering entire comprehensive curriculum contents, and to train students in mastering deep and comprehensive manufacturing knowledge. In a word, gamification can be applied to make learning more engaging, but it should not be viewed as isolation to classroom teaching and hand-on training.

d) Reward mechanism should be achievable

We agree that rewards should be achievable with a sufficient level of effort. It is important to create conditions and opportunities to achieve the ultimate goal. Each level of task is expected to be more complex and require more efforts corresponding to newly acquired knowledge and skills. By repetitive trials, students can improve their skills as well as achieve better ranking. We also agree that gamification should be used to increase motivation, but may not an effective mechanism to grade students [7]. It is not always the case that a student at the top of leaderboard is the best achiever in formal assessment.

e) Motivation could be related to intrinsic and extrinsic characteristics 
We noted that some arguments exist in terms of the motivation by gamification in regard to individual's intrinsic and extrinsic characteristics. Groh found that gamification seeks to increase motivation by providing extrinsic recognition and reward for completing activities, however there is the possibility that such rewards can serve to de-motivate learners with an already high intrinsic motivation [8]. Similarly, Olsson [9] argued that some of the variance in the effectiveness of gaming mechanisms depend on the learner's intrinsic motivation. These arguments need further studies in order to optimize gaming tasks and mechanism with respect to the individual's characteristics.

During the implementation phase, we noticed two limitations of the current gaming platform. One is that students expect more gaming tasks covering their teaching curriculum. The other is the lack of the gaming scenarios and consequences caused by mistakes or wrong operations. These limitations will be considered in future work. In addition, the in-game perception of students' intrinsic and extrinsic motivation has not been taken into consideration in our current work. One possible approach is to embed intelligent data analytics methods into the gamification platform to perform learning behavior \& pattern perception.

Author Contributions: The presented work in this paper comprises of several key parts, i.e. the methodology design, software and VR replica development, the implementation and data collection of the gamification platform in T\&L at NYP. The contributions of authors are: Conceptualization, Zhao Zhiqiang and Wong Yuen Choe; methodology and architecture, Zhao Zhiqiang and Toh Da Jun; software, Zhao Zhiqiang, Toh Da Jun and Ding Xiaoming; implementation and data collection in T\&L, Ng Keng Chong and Sin See Choon.

Acknowledgments: The presented work has been supported by the Centre of Digital \& Precision Engineering of School of Engineering of Nanyang Polytechnic including all ICT facilities and the shopfloor space.

Conflicts of Interest: "The authors declare no conflict of interest."

\section{References}

1. Juho Hamari, Jonna Koivisto and Harri Sarsa. Does Gamification Work? - A Literature Review of Empirical Studies on Gamification. The 2014 47th Hawaii International Conference on System Science, 2014

2. Christensen and Raynor. The Innovator's Solution: Creating and Sustaining Successful Growth, Harvard University Press, Cambridge, MA. ISBN: 978-1578518524, 2003

3. Ilaria Caponetto, Jeffrey Earp and Michela Ott. Gamification and Education: A Literature Review, 2014, https://www.itd.cnr.it/download/gamificationECGBL2014.pdf, Accessed in Oct. 2018

4. Bradley Wiggins. An Overview and Study on the Use of Games, Simulations, and Gamification in Higher Education, International Journal of Game-Based Learning, v6 n1 p18-29 2016

5. Oxford Analytica. Gamification and the Future of Education, 2026 https://www.worldgovernmentsummit.org/api/publications/document?id=2b0d6ac4-e97c-6578-b2f8-ffo000a7ddb6, Accessed in Oct. 2018

6. Yu-kai Chou. (2017). Gamification in Education: Top 10 Gamification Case Studies that will Change our Future. 2017, http://ec.europa.eu/programmes/proxy/alfrescowebscripts/api/node/content/workspace/SpacesStorele22ddbda-dd23-42cc-89a2786e921b2d80/Gamification\%20in\%20Education_20170418_020301.pdf, Accessed in Oct. 2018

7. Ian Glover. Play As You Learn: Gamification as a Technique for Motivating Learners. Proceedings of World Conference on Educational Multimedia, Hypermedia and Telecommunications 2013.

8. Fabian Groh. Gamification: State of the Art Definition and Utilization. In Proceedings of the 4th Seminar on Research Trends in Media Informatics, Institute of Media Informatics, Ulm University. 2012

9. Marie Olsson, Peter Mozelius and Jonas Collin. Visualisation and Gamification of e-Learning - Attitudes Among Course Participants, ICEL 2015, 10th International Conference on e-Learning. 2015 